\title{
PERFIL SOCIODEMOGRÁFICO E DE SAÚDE DE MULHERES SOROPOSITIVAS EM UM PRÉ-NATAL DE ALTO RISCO*
}

Camila Fernandes da Silva Carvalho', Richardson Augusto Rosendo da Silva²

'Enfermeira. Universidade Federal do Rio Grande do Norte. Natal-RN-Brasil.

2Enfermeiro. Doutor em Ciências da Saúde. Universidade Federal do Rio Grande do Norte. Natal-RN-Brasil.

RESUMO: Estudo transversal, descritivo e documental, o qual descreve o perfil sociodemográfico e de saúde das 47 gestantes soropositivas para o vírus da imunodeficiência humana em um pré-natal de alto risco, com corte temporal de 2008 a 2012. O perfil caracterizou-se por gestantes com idade média de 27 anos, não brancas, com escolaridade entre o Ensino Fundamental e Médio, em união estável, donas de casa, residindo no interior do Estado, primigestas ou secundigestas e primíparas, com média de cinco consultas pré-natais, iniciado com 14 semanas de gestação ou mais, em uso de Biovir ${ }^{\circledR}$ e Kaletra ${ }^{\circledR}$, e negaram uso de drogas e diagnóstico para o vírus anterior à gestação atual. Concluiu-se ser necessário conhecer o perfil da gestante soropositiva visando planejar ações que favoreçam a assistência; padronizar os registros e readequar o pré-natal de alto risco segundo as diretrizes do Ministério da Saúde do Brasil.

DESCRITORES: Enfermagem materno-infantil; Transmissão vertical de doença infecciosa; Gestantes; HIV.

\section{SOCIO-DEMOGRAPHIC AND HEALTH PROFILE OF SEROPOSITIVE WOMEN IN HIGH-RISK PRE- NATAL CARE}

\begin{abstract}
This transversal, descriptive and documental study describes the socio-demographic and health profile of 47 pregnant women, seropositive for the Human Immunodeficiency Virus in high-risk prenatal care, between 2008 - 2012. The profile is characterized by pregnant women with a mean age of 27 years old, nonwhites, with an educational level of Junior and Senior High School, in stable relationships, housewives, living in non-metropolitan parts of the state, primigravidas or secundigravidas and primiparous, with a mean of five prenatal consultations, initiated at the 14th week of pregnancy or later, using Biovir ${ }^{\circledR}$ and Kaletra ${ }^{\circledR}$, and who denied taking drugs and being diagnosed for the virus prior to the current pregnancy. It is concluded that it is necessary to know the profile of the seropositive pregnant woman with a view to: planning actions promoting care; standardizing the records, and; re-adjusting high-risk prenatal care in accordance with Brazilian Ministry of Health guidelines. DESCRIPTORS: Mother and Child Nursing; Vertical transmission of infectious diseases; pregnant women; HIV.
\end{abstract}

\section{PERFIL SOCIODEMOGRÁFICO Y DE SALUD DE MUJERES SEROPOSITIVAS EN UN PRENATAL DE ALTO RIESGO}

RESUMEN: Estudio transversal, descriptivo y documental, lo cual describe el perfil sociodemográfico y de salud de 47 gestantes seropositivas para el virus de la inmunodeficiencia humana en un prenatal de alto riesgo, con corte temporal de 2008 a 2012. El perfil se caracterizó por contener gestantes con edad media de 27 años, no blancas, con escolaridad entre la Enseñanza Fundamental y Medio, en unión estable, amas de casa, que vivían en interior del Estado, de primera o segunda gestación y primíparas, con media de cinco consultas prenatales, iniciadas con 14 semanas de gestación o más, en uso de Biovir ${ }^{\circledR}$ y Kaletra ${ }^{\circledR}$. Las mujeres negaron usar drogas, así como el hecho del diagnóstico para el virus ser anterior a la gestación actual. Se concluye que es necesario conocer el perfil de la gestante seropositiva con fines de planear acciones que ayuden en la asistencia; estandarizar los registros y readecuar el prenatal de alto riesgo de acuerdo a las directrices del Ministerio de la Salud de Brasil.

DESCRIPTORES: Enfermería materno-infantil; Transmisión vertical de enfermedad infecciosa; Gestantes; HIV.

*Trabalho de Conclusão do Curso de Graduação em Enfermagem da Universidade Federal do Rio Grande do Norte, 2012.

\section{Autor Correspondente:}

Richardson Augusto Rosendo da Silva

Universidade Federal do Rio Grande do Norte

Lagoa Nova, s/n - 78048-298 - Natal-RN-Brasil

E-mail: rirosendo@yahoo.com.br 


\section{INTRODUÇÃO}

Os primeiros casos da Síndrome da Imunodeficiência Humana (HIV/aids) em mulheres ocorreram na década de 1980, porém em números menores em relação à infecção masculina. Ao longo dos anos, a evolução das ações da prevenção feminina para o HIV foi lenta e tardia, refletindo no aumento progressivo do número de mulheres soropositivas ${ }^{(1)}$. No Brasil, o cenário atual reflete a razão de 1,9 homens infectados para cada mulher também com HIV(2). Além disso, o perfil da mulher soropositiva brasileira corresponde ao encontrado globalmente: nível socioeconômico e de educação baixos e em relacionamento estável a qual não é atendida pelo seu parceiro quando solicita o uso de preservativo ${ }^{(3)}$.

A feminização da epidemia se constitui como um fator de risco para a transmissão vertical (TV) do vírus, ou seja, da infecção do feto durante o período intrauterino (35\%), trabalho de parto (65\%) e/ou durante a amamentação $(7-22 \%)^{(4)}$. Portanto, a TV foi o principal ponto que levou a uma maior visibilidade da feminização da epidemia de HIV/aids.

Diante destes riscos eminentes, o Ministério da Saúde do Brasil (MS) decretou medidas para serem implantadas em toda rede de saúde, a saber: educação sexual e orientação sobre HIV de forma dialogada com suporte profissional; realização do teste anti-HIV a toda gestante com sorologia desconhecida, mediante o seu consentimento e garantindo a confidencialidade; início da Terapia Antirretroviral (TARV) a gestantes HIV positivo até, no máximo, na $14^{\mathrm{a}}$ semana de gestação sob o acompanhamento do profissional de saúde e uso do medicamento injetável durante o trabalho de parto; realização do parto cesariano eletivo em pacientes a partir da $34^{\text {a }}$ semana com carga viral $>1000$ cópias $/ \mathrm{mL}$ ou indisponível; orientação e uso de métodos supressores do aleitamento materno, oferecendo ao filho a fórmula infantil disponibilizada pelas unidades de saúde; indicação do uso do medicamento profilático oral ao recém-nascido até a $6^{a}$ semana e acompanhamento através de bateria de exames até os 18 meses ${ }^{(5)}$.

No Rio Grande do Norte (RN), Nordeste do Brasil, observa-se que a incidência em relação a sexo no ano de 2012 foi de 2,5 homens para uma mulher infectada. Além disso, em 2013 o coeficiente de gestantes soropositivas foi 1,4 para cada 1.000 nascidos vivos, sendo esse número elevado em relação aos obtidos nos anos anteriores. Constata-se, deste modo, a suscetibilidade de crianças expostas ao vírus $^{(2,6)}$.

Sabendo-se que a transmissão vertical é a principal via de transmissão do HIV em crianças no Brasil e no $R N^{(6)}$, partiu-se da seguinte questão norteadora: "Qual o perfil da mulher gestante soropositiva no Rio Grande do Norte?". Diante dessa problemática, o estudo objetivou descrever o perfil sociodemográfico e de saúde das gestantes soropositivas para HIV em um pré-natal de alto risco.

Nesse sentido, espera-se que o conhecimento da realidade epidemiológica dessa população sirva como subsídio para profissionais da saúde planejar ações focalizadas a esse público-alvo, gerando implemento à assistência de qualidade no pré-natal e, consequentemente, diminuição dos riscos da transmissão materno-infantil do HIV.

\section{MÉTODO}

Pesquisa transversal, descritiva do tipo documental com tratamento quantitativo dos dados. O local de estudo foi o setor de PréNatal de Alto Risco (PNAR) da Maternidade Escola Januário Cicco. A mesma é um Hospital Escola da Universidade Federal do Rio Grande do Norte e principal centro de referência para o tratamento de gestantes soropositivas no Estado.

A população consistiu de 55 prontuários das gestantes portadoras de HIV/aids cujos registros estavam no livro da Infectologia do PNAR entre o período de 2008 a 2012. Os critérios inclusivos foram todas as gestantes comprovadamente portadoras do vírus HIV/aids, residentes no Rio Grande do Norte, com prontuário de prénatal localizado no Arquivo da MEJC e que possuíam os dados sociodemográficos e de saúde preenchidos em seu prontuário.

A coleta de dados realizou-se por meio dos números de registro encontrados no livro do PNAR no mês de agosto de 2012, os quais permitiam localizar os prontuários das 
usuárias no Arquivo do MEJC. Assim, obtevese 47 prontuários que atendiam os critérios supracitados.

Os dados obtidos dos prontuários seguiram a um roteiro pré-estabelecido contendo as seguintes informações: idade que a gestante possuía no momento da consulta, cor, escolaridade, ocupação, estado civil e local de residência. Além disso, abordava a idade gestacional na primeira consulta pré-natal e a quantidade desta, número de gestações e partos anteriores, abortos, uso de drogas lícitas e/ou ilícitas, ano do seu diagnóstico e do seu parceiro e o uso de contraceptivos. Esses dados foram tabulados, receberam tratamento estatístico através do programa de informática Microsoft Office Excel 2007® e foram organizados em dois quadros (dados sociodemográficos e dados obstétricos) constando as variáveis relevantes em frequência e percentuais.

Essa pesquisa foi submetida ao Comitê de Ética em Pesquisa da Liga Norte Rio-grandense Contra o Câncer com parecer favorável n. 65443 e CAAE n. 02918612.2.0000.5293. O estudo seguiu a resolução do Conselho Nacional da Saúde sobre preceitos éticos em pesquisa envolvendo seres humanos, assegurando a privacidade e confidencialidade das usuárias.

\section{RESULTADOS}

Quanto às características sociodemográficos das 47 gestantes soropositivas observou-se que a média de idade foi de 26,8 anos, sendo a mais jovem de 16 anos e a de maior idade de 40 anos. A maioria possuía na primeira consulta de pré-natal de 21-30 anos, cor não branca, ensino médio incompleto, ocupação do lar, união estável e proveniente do interior do estado. Os dados podem ser visualizados no Quadro 1.

O Quadro 2 delineia os dados dos pré-natais das 47 gestações investigadas entre 2008-2012 no PNAR, com média de 4,6 consultas. Os exames com resultado da carga viral e do CD4 foram registrados em 29 e 28 prontuários respectivamente. A parte majoritária das gestantes realizou durante o seguimento do pré-natal o uso de Biovir ${ }^{\circledR}$ (Zidovudina + Lamivudina) e Kaletra ${ }^{\circledR}$ (Lopinavir + Ritonavir). Houve sete casos de modificação no tratamento por conta dos resultados da carga viral e cluster of differentation - 4 (CD4) e dois casos devido a reações adversas relacionadas à elevação de transaminase glutâmico oxalacética (TGO) e transaminase glutâmico pirúvica (TGP) e a Síndrome de Steven-Johnson. Foram detectados 15 relatos de Doenças Sexualmente Transmissíveis (DST) pregressa ou atual. Todas tinham indicação de interrupção da gravidez por via abdominal em seus prontuários.

Quadro 1 - Características sociodemográficas de gestantes com HIV/aids entre 2008-2012. Natal-RN-Brasil, 2012

\begin{tabular}{|l|l|c|c|}
\hline Variáveis & Categorias & $\mathrm{n}$ & $\%$ \\
\hline \multirow{4}{*}{$\begin{array}{l}\text { Idade na primeir } \\
\text { consulta pré-natal }\end{array}$} & $\leq 16$ anos & 1 & 2,13 \\
\cline { 2 - 4 } & $17-20$ anos & 6 & 12,77 \\
\cline { 2 - 4 } & $21-30$ anos & 29 & 61,70 \\
\cline { 2 - 4 } & $>30$ anos & 11 & 23,40 \\
\hline \multirow{3}{*}{ Cor } & Branca & 13 & 27,66 \\
\cline { 2 - 4 } & Não Branca & 34 & 72,34 \\
\hline \multirow{3}{*}{ Escolaridade } & Ensino Fundamental Completo & 23 & 48,94 \\
\cline { 2 - 4 } & Ensino Médio Incompleto & 24 & 51,06 \\
\hline \multirow{3}{*}{ Estado Civil } & Autônoma & 8 & 17,02 \\
\cline { 2 - 4 } & Empregada assalariada & 9 & 19,15 \\
\cline { 2 - 4 } & Do lar & 30 & 63,83 \\
\hline \multirow{2}{*}{ Residência } & Solteira & 13 & 27,66 \\
\cline { 2 - 4 } & União Estável & 34 & 72,34 \\
\hline Total & Natal & 23 & 48,94 \\
\cline { 2 - 4 } & Interior & 24 & 51,06 \\
\hline
\end{tabular}


Quadro 2 - Características dos dados obstétricos de gestantes com HIV/aids entre 2008-2012. Natal-RN-Brasil, 2012

\begin{tabular}{|c|c|c|c|}
\hline Variáveis & Categorias & $\mathbf{n}$ & $\%$ \\
\hline \multirow{2}{*}{$\begin{array}{l}\text { Idade Gestacional na } \\
\text { primeira consulta pré- } \\
\text { natal }\end{array}$} & $<14^{\mathrm{a}}$ semana & 11 & 23,40 \\
\hline & $\geq 14^{\mathrm{a}}$ semana & 36 & 76,60 \\
\hline \multirow{2}{*}{$\begin{array}{l}\text { Número de consultas } \\
\text { pré-natal }\end{array}$} & $<6$ consultas & 31 & 65,96 \\
\hline & $\geq 6$ consultas & 16 & 34,04 \\
\hline \multirow{5}{*}{ Número de gestações } & 1 gestação & 15 & 31,91 \\
\hline & 2 gestações & 15 & 31,91 \\
\hline & 3 gestações & 10 & 21,28 \\
\hline & 4 gestações & 4 & 8,51 \\
\hline & $\geq 5$ gestações & 3 & 6,39 \\
\hline \multirow{2}{*}{ Aborto } & Sim & 13 & 27,66 \\
\hline & Não & 34 & 72,34 \\
\hline \multirow{4}{*}{$\begin{array}{l}\text { Número de partos } \\
\text { anteriores }\end{array}$} & Nenhum parto & 17 & 36,17 \\
\hline & 1 parto & 22 & 46,81 \\
\hline & 2 partos & 5 & 10,64 \\
\hline & $\geq 3$ partos & 3 & 6,38 \\
\hline \multirow{2}{*}{ Uso de drogas } & Sim & 7 & 14,89 \\
\hline & Não & 40 & 85,11 \\
\hline \multirow{3}{*}{$\begin{array}{l}\text { M o m e n t o d o } \\
\text { diagnóstico de HIV da } \\
\text { gestante }\end{array}$} & Anterior à gestação & 19 & 40,42 \\
\hline & Atual gestação & 17 & 36,18 \\
\hline & Não há registro & 11 & 23,40 \\
\hline \multirow{4}{*}{$\begin{array}{l}\text { Diagnóstico de HIV do } \\
\text { parceiro }\end{array}$} & Soropositivo & 8 & 17,02 \\
\hline & Soronegativo & 4 & 8,51 \\
\hline & Não realizou/recusou & 2 & 4,25 \\
\hline & Não há registro & 33 & 70,22 \\
\hline \multirow{3}{*}{$\begin{array}{l}\text { Uso de métodos } \\
\text { contraceptivos }\end{array}$} & Confirmam & 14 & 29,79 \\
\hline & Negam & 2 & 4,25 \\
\hline & Não há registro & 31 & 65,96 \\
\hline Total & & 47 & $100 \%$ \\
\hline
\end{tabular}

\section{DISCUSSÃO}

As gestantes HIV positivo eram em sua maioria adultas jovens, fase em que se encontram sexualmente ativas e em plena idade reprodutiva, constituindo o grupo etário de maior incidência da doença ${ }^{(7)}$. Em relação à cor, os achados dessa pesquisa condizem com a realidade da população brasileira, composta pela mixagem de etnias, porém contradiz com os dados epidemiológicos referentes às mulheres com HIV no Brasil, pois o predomínio é maior entre as que se autodeclararam brancas ${ }^{(2)}$.
Nesse estudo, a escolaridade das gestantes encontravam-se entre o Ensino Fundamental (48,9\%) e Ensino Médio (51,0\%), apresentando assim resultados melhores em relação ao estudo realizado no Pará(8) e semelhante ao realizado no Ceará ${ }^{(9)}$ como também aos dados nacionais ${ }^{(2)}$. A ocupação "do lar" está também de acordo com as pesquisas realizadas em outros estados do Brasil( $^{(7,9)}$ e reflete que, historicamente, a responsabilidade nos cuidados domésticos e na educação dos filhos recaem na figura feminina da família. Portanto, essas gestantes têm tempo reduzido para se dedicar a seu autocuidado como aderir às medidas profiláticas e ir regularmente 
ao pré-natal. Assim, a ocupação da mulher pode ser considerada de forma indireta um risco de transmissão materno-infantil do HIV(9-10).

A prevalência da soropositividade nesse estudo sucede nas gestantes que residiam fora da capital (51,06\%). O processo de interiorização do HIV iniciou concomitante com a feminização, porém sua expansão ocorre diferentemente em cada região do país ${ }^{(1)}$. Outro estudo mostra o aumento da incidência de casos de gestantes HIV positivo na zona rural ${ }^{(9)}$.

Ter um companheiro fixo no período do seguimento do pré-natal esteve presente nas respostas de $72,3 \%$ mulheres. Considerando que a principal forma de infecção dessas mulheres é a via sexual, entende-se que o parceiro atual também está infectado, ou é soronegativo, estando exposto ao vírus. No entanto, neste estudo, constatou-se que das 47 gestantes acompanhadas no pré-natal, não havia esta informação registrada em 33 prontuários. Assim, torna-se imprescindível o conhecimento da sorologia do parceiro dessas gestantes ${ }^{(11)}$, pois a ausência desse dado dificulta o rastreamento do parceiro e o desenvolvimento de atividades educativas e profiláticas com o casal.

Além disso, 33 mulheres já tinham filhos, o que torna imperativo o rastreamento dos susceptíveis de infecção em torno dessa mulher. Porém o registro da sorologia dos filhos não estão disponíveis nos prontuários. Nesse sentido, ressalta-se a importância da valorização do núcleo familiar durante as consultas de pré-natal, o registro de informações precisas para o devido acompanhamento e profilaxia, assim como no desenvolvimento de estudos epidemiológicos.

As mulheres desse estudo, em sua maioria, tiveram seu diagnóstico de HIV positivo em gestações anteriores. Subentende-se que o conhecimento da sua soropositividade e a descoberta da gravidez levaram as unidades de saúde encaminhá-las ao PNAR/MEJC, refletindo a importância de serviço especializado na profilaxia para HIV. Porém, não há informação se essas mulheres iniciaram a TARV nos serviços de origem haja vista que a idade gestacional na primeira consulta realizada na PNAR foi, em sua maioria, acima da $14^{\mathrm{a}}$ semana, período considerado tardio para a profilaxia ${ }^{(5)}$, configurando assim a importância de ter esse dados precisos nos prontuários.
Ao relacionar o ano da consulta com a data do diagnóstico de HIV e com os registros das consultas durante o pré-natal sobre a medicação, cinco mulheres HIV positivo da amostra não estavam em uso do antirretroviral antes da gravidez atual, dentre as quais três já estiveram grávidas anteriormente, e uma relatou que só usou no intraparto da sua última gestação. $\mathrm{O}$ uso do antirretroviral é imprescindível para a efetivação da profilaxia gestacional desde antes da gravidez para que a prevenção da transmissão vertical seja efetiva ${ }^{(5)}$. Assim, dados registrados são importantes para investigar acerca das crianças expostas e se medidas foram tomadas em relação a possível infecção.

O Ministério da Saúde do Brasil preconiza o mínimo de seis consultas pré-natais, porém como se trata de gestação de alto risco, o número de consultas deve ser maior do que recomendado às demais gestantes ${ }^{(5)}$.

A quantidade de consultas pré-natais no PNAR está abaixo do recomendado em 65,96\% dos casos, fato preocupante, pois significa que o acompanhamento não foi efetivo o suficiente para garantir o desenvolvimento das medidas profiláticas para a redução da transmissão vertical do HIV/aids.

As gestantes do estudo são primigestas ou secundigestas e primíparas. Levando em consideração que $40,42 \%$ tiveram o resultado do diagnóstico de HIV positivo anterior à gestação investigada, podemos inferir que a infecção não impediu o desejo pela maternidade, tal como ocorreu no estudo realizado em Fortaleza-Ceará, Brasil $^{(12)}$. Não foi possível constatar se a gravidez foi planejada e acompanhada por profissionais de saúde, devido ao sub-registro de 65,96\% dos casos sobre uso de contraceptivo, assim como a inexistência de informação sobre o planejamento familiar nos prontuários. Além disso, destaca-se a incidência de 27,66\% de aborto na amostra. Esse número é expressivo e importante epidemiologicamente para a assistência devido às implicações sociais, psicológicas e de saúde que envolve o evento somado ao impacto proporcionado pela soropositividade.

Os casos de DST devem ser investigados, porque é um fator de risco para o HIV e pode ser responsável pela ocorrência de gestações ectópicas, abortos e natimortos, principalmente quando a doença não é tratada ${ }^{(1)}$. No presente 
estudo constatou que 31,91\% das gestantes possuíam algum tipo de DST. Nesse sentido, o diagnóstico precoce de DST, inclusive HIV, deve ser aprimorado no pré-natal e nas consultas que aborda a saúde da mulher na Atenção Básica ${ }^{(1,13)}$.

As recomendações preventivas do MS permitem que a gestante HIV positivo tenha a via vaginal como opção de parto, desde que o seu status imunológico esteja dentro dos parâmetros seguros, delineados anteriormente, e seja submetida aos cuidados profiláticos do intraparto como o uso do AZT intravenoso, a ausência de procedimentos invasivos e a manutenção da integridade das membranas amnióticas ou a realização do parto com menos de 4 horas da sua ruptura(5).

A indicação absoluta do parto cesariano as gestantes investigadas após a $37^{\mathrm{a}}$ semana e a ausência dos dados de CD4 e carga viral em vários prontuários, inclusive no terceiro trimestre, aponta a necessidade de mais estudos para compreender a rotina intraparto da maternidade baseado nas recomendações do MS. Assim, o resultado diverge em relação ao encontrado em outros estudos, os quais apontam que o parto por via vaginal foi predominante nas suas amostras $^{(7,14)}$.

Nesse estudo, $14 \%$ das gestantes referiram usar algum tipo de droga. As drogas injetáveis com agulhas compartilhadas são o segundo fator principal de infecção por HIV, porém é responsável por maior número de mortalidade, mesmo em uso do TARV(1). As drogas potencializam os danos provocados pela infecção da HIV e diminui a capacidade de julgamento e tomada de decisão em situações de risco como, por exemplo, no momento de decisão do uso de preservativo durante a relação sexual e, no caso dos adolescentes, o início precoce da atividade sexual ${ }^{(1,7)}$.

Entre os 14 registros que confirmaram o uso de contraceptivos, o condom masculino foi o mais mencionado, sendo este o método de barreira mais efetivo e recomendado em HIV soropositivo para evitar transmissão de DST, infecção por HIV em companheiro soronegativo ou infecção por vírus resistente e aumento da carga viral em casais concordantes, além de evitar gravidez não planejada ${ }^{(5,11)}$. Recomenda-se a combinação de métodos para reforçar essa proteção, porém apenas uma ocorrência foi registrada entre os prontuários, na qual consistia o contraceptivo hormonal injetável e o condom. As demais mulheres que referiram usar outros métodos de caráter hormonal precisam ser instruídas a adotar também os métodos de barreiras. Deve-se dar a devida importância a essa questão principalmente pelo comportamento de risco que o companheiro possa assumir, mesmo que o relacionamento seja considerado estável ${ }^{(11)}$.

\section{CONSIDERAÇÕES FINAIS}

O perfil da gestante HIV positivo nessa pesquisa corresponde ao encontrado nos estudos brasileiros e mundiais: jovens, não brancas, nível socioeconômico baixo e em relacionamento estável sem o hábito do uso de contraceptivo de barreira nas relações sexuais, caracterizando a vulnerabilidade dessa população. Identificouse também que a maioria residia no interior do Estado, eram primíparas, com média de cinco consultas pré-natais, iniciado no segundo trimestre de gestação ou mais, em uso de Biovir $₫$ e Kaletra® no seguimento e diagnóstico HIV positivo anterior à atual gestação.

Esse estudo apresenta limitação ao desconhecer se o encaminhamento para o PNAR está adequado, principalmente a referência procedente do interior do estado e se isso está contribuindo para os achados supracitados.

Observou-se a necessidade urgente de padronizar os registros dos prontuários no atendimento à mulher soropositiva que permita melhor qualidade no seguimento até o momento do parto. Para isso, necessita-se também promover a atualização e capacitação dos profissionais de saúde quanto às diretrizes do MS para prevenção da TV nos pré-natais e o direcionamento de suas ações ao perfil sociodemográfico dessas mulheres, incentivando a presença de uma equipe multiprofissional nas consultas pré-natais de risco elevado.

Também, a equipe de Enfermagem deve estar mais presente para promover o autocuidado das mulheres HIV positivo. O enfermeiro deve estar ativo na educação e prevenção dessas mulheres em idade reprodutiva para diminuir o número de soropositivas e, caso possua a sorologia, prevenir a transmissão materno-infantil do HIV. 


\section{REFERÊNCIAS}

1. Ministério da Saúde (BR). Plano integrado de enfrentamento da feminização da epidemia de AIDS e outras DST. Versão revisada - Setembro de 2011. Brasília: Ministério da Saúde; 2011.

2. Ministério da Saúde (BR). Boletim epidemiológico HIV - AIDS. Brasília: Ministério da Saúde; 2013.

3. Carvalho CFS, Silva RAR. Medidas profiláticas para a redução da transmissão vertical de HIV no Brasil: estudo informativo. Rev. enferm. UFPE. [Internet] 2013;7(9) [acesso em 23 jan 2014]. Disponível: http:// www.revista.ufpe.br/revistaenfermagem/index.php/ revista/article/download/4792/7188

4. Ministério da Saúde (BR). Atenção ao pré-natal de baixo risco. Cadernos de atenção básica n 32. Brasília: Ministério da Saúde; 2013.

5. Ministério da Saúde (BR). Recomendações para profilaxia da transmissão vertical do HIV e terapia antirretroviral em gestantes. Brasília: Ministério da Saúde; 2010.

6. Secretaria Estadual de Saúde (RN). Boletim epidemiológico DST/Aids/Hepatites virais. Natal: Secretaria Estadual de Saúde; 2013.

7. Manenti SA, Júnior JG, Silveira ES, Oenning RT, Simões PWTA, Moreira J, et al. Epidemiologic and clinical characteristics of pregnant women living with HIV/AIDS in a region of Southern Brazil where the subtype C of HIV-1 infection predominates. Braz J Infect Dis. [Internet] 2011;15(4) [acesso em 26 jul 2012]. Disponível: http://dx.doi.org/10.1590/S141386702011000400008

8. Meneses LSH, Palacios VRCM, Peixoto CAS, Alcântara MSV, Carneiro CN. Perfil epidemiológico de grávidas HIV positivas atendidas em maternidade pública de referência. Rev. Para. Med. [Internet] 2013;27(2) [acesso em 24 jan 2014]. Disponível: http://files.bvs. br/upload/S/0101-5907/2013/v27n2/a3676.pdf

9. Gonçalves MLC, Silva HO, Oliveira TA, Rodrigues LV, Campos ALA. Perfil sociodemográfico e obstétrico de puérperas assistidas no município de Iguatu - CE. Rev Bras Promo. Saúde. [Internet] 2012;25(Suppl 2):33-9. Disponível: http://ojs.unifor.br/index.php/RBPS/article/ view/2242/2469.

10. Langendorf TF, Padoin SMM, Paula CC, Silva CB. Vulnerabilidade na adesão à profilaxia da transmissão vertical do HIV. Cogitare enferm [Internet] 2012;17(4) [ acesso em 21 jan 2013]. Disponível: http://ojs.c3sl.ufpr.br/ojs2/index.php/cogitare/article/ viewFile/30388/19663. puérperas com HIV/AIDS: conhecendo os déficits e os fatores que contribuem no engajamento para o autocuidado. Esc. Anna Nery. [Internet] 2009;13(2) [acesso em 22 jul 2011]. Disponível: http://www.eean. ufrj.br/revista_enf/20092/artigo\%2015.pdf.

12. Galvão MTG, Cunha GH, Machado MMT. Dilemas e conflitos de ser mãe na vigência do HIV/Aids. Rev. bras. enferm. [Internet] 2010;63(3) [acesso 11 março 2012]. Disponível: http://dx.doi.org/10.1590/S003471672010000300004.

13. Barbosa RCM. Validação de um vídeo educativo para a promoção do apego seguro entre mãe soropositiva para o HIV e seu filho [tese]. Fortaleza (CE): Universidade Federal do Ceará; 2008. 120 f. Disponível: http://www. teses.ufc.br/tde_busca/arquivo.php?codArquivo=3037.

14. Baldasso EKF. Avaliação da testagem rápida para o HIV em parturientes de uma maternidade pública de Dourados, Mato Grosso do Sul [dissertação]. Campo Grande (MS): Escola Nacional Saúde Pública Sérgio Arouca; 2010. 73 p. Disponível: http://bvssp.icict. fiocruz.br/lildbi/docsonline/get.php?id=2277

11. Scherer LM, Borenstein MS, Padilha MI. Gestantes/ 